Gut, 1962, 3, 224

\title{
The case for total gastrectomy in multiple polyposis of the stomach
}

\author{
R. A. ROXBURGH \\ From the Central Middlesex Hospital, London
}

EDITORIAL SYNOPSIS There is a considerable risk that a patient with multiple polyposis of the stomach will develop carcinoma of the stomach and this risk is greater than that of total gastrectomy when performed for benign conditions. Total gastrectomy is therefore sound treatment for this disease, regardless of the distribution of the lesions over the gastric mucosa, and a patient successfully treated in this way is reported. Reference is also made to a patient who died untreated and was found to have both multiple polyposis and gastric carcinoma.

Adenomatosis of the stomach, often called multiple polyposis, is a rare disease that poses considerable difficulties in its pathology, diagnosis, and management. Stewart (1929) found 10 examples with more than four adenomata in 11,000 necropsies, and this gives a post-mortem incidence of $0.09 \%$, and Yarnis, Marshak, and Friedman (1952) also found a postmortem incidence of $0.09 \%$ for multiple polyps but it is met with clinically even more infrequently than this. The disease, which is seldom encountered before middle age and which afflicts men at least twice as often as women, hardly ever has a familial tendency. It frequently causes no symptoms but even when it does they are seldom very severe and may have been present for a long time. The commonest symptom is vague epigastric discomfort; less common are vomiting, anorexia, diarrhoea, and weakness. Pearl and Brunn (1943) found that $52 \%$ of 41 patients with multiple adenomata had evidence of some form of bleeding, and in $19 \%$ of the 41 it took the form of a haematemesis which was sometimes of serious proportions. Lesser degrees of bleeding in the form of a continuous ooze are a contributory cause of the anaemia that is often present. Occasionally the anaemia is of the pernicious type.

CASE REPORTS

CASE 1 Miss R.S.M., aged 51, was admitted on 4 October 1960 complaining of weakness and of bleeding haemorrhoids for two months. Haemoglobin was $60 \%$. She was transfused and the haemorrhoids were injected. She stated that she had had some dysphagia for 20 years, intermittent indigestion for 10 years, and a recent attack of severe epigastric pain severe enough to keep her awake during the night following its onset. The pain eased and was succeeded by a dull epigastric ache that came on an hour after food and was slightly relieved by drinking milk. She had vomited on several occasions in the two months preceding admission and at the same time had lost her interest in food. There had been no haematemesis. She had been easily fatigued for a year. Her weight was steady. She had suffered from no diseases of consequence in the past and there was no history of stomach disorder in the family.

On examination she was tender in the epigastrium, but apart from this and the haemorrhoids there were no other abnormal physical signs. There was no evidence of the Peutz-Jeghers syndrome.

Investigations $\mathrm{Hb}$ was $95 \%$, a film normal, W.B.C. 3,200/c.mm., E.S.R. $81 \mathrm{~mm}$. in one hour (Westergren), group $\mathrm{O}, \mathrm{Rh}$ positive. Serum proteins were not estimated. Sigmoidoscopy was normal to $13 \mathrm{~cm}$. and no polyps were seen. An augmented histamine test meal (Kay) showed total achlorhydria. Gastroscopy (Dr. F. Avery Jones) showed gross polypoidal changes on the posterior wall and again lower down on the anterior wall near the angulus, with scattered small polyps elsewhere. There was no definite evidence of malignancy. The report on a barium meal (Fig. 1) stated that the oesophagus appeared normal. Barium entered the stomach normally. Multiple polypoidal filling defects were shown occupying the greater part of the body of the stomach. The duodenal cap was normal. Barium was followed through the small bowel to the caecum and proximal colon and no abnormality was seen. The diagnosis was polyposis of the stomach, probably associated with carcinomatous changes.

Operation (Mr. J. W. P. Gummer) On 11 January 1961 total gastrectomy was performed via an abdominothoracic incision. Continuity was restored by an oesophago-jejunostomy en-Y. The stomach felt virtually normal; at most it could be said to have felt a little thick-walled but certainly no adenomata could be felt through the wall. The patient's subsequent course was 


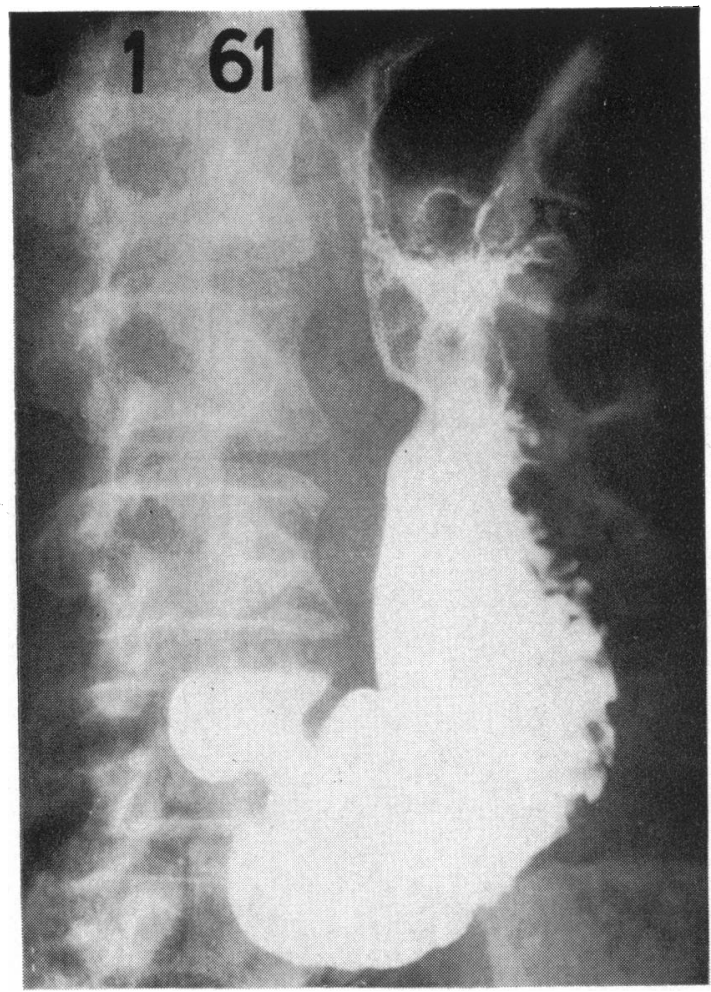

FIG. 1. Barium meal showing multiple polypoidal filling defects.

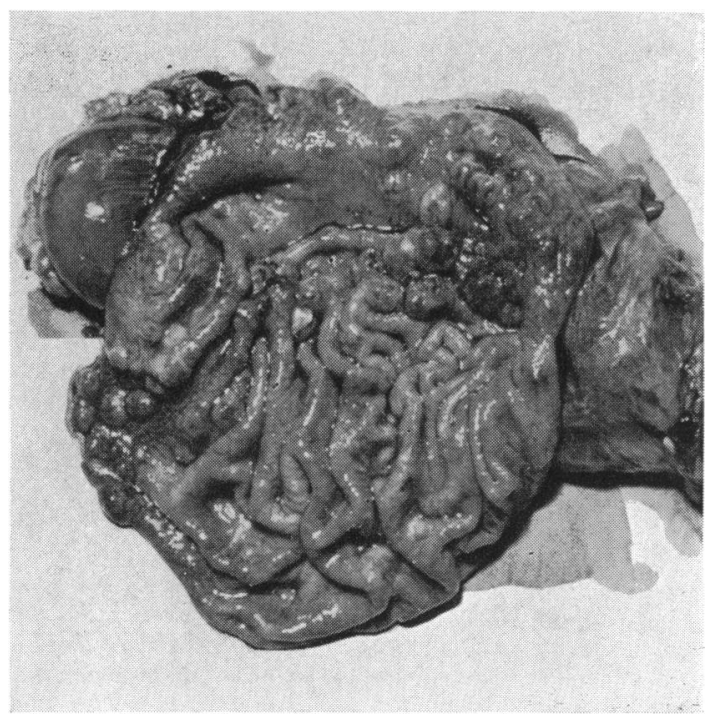

FIG. 2. Total gastrectomy specimen showing widespread adenomatosis.

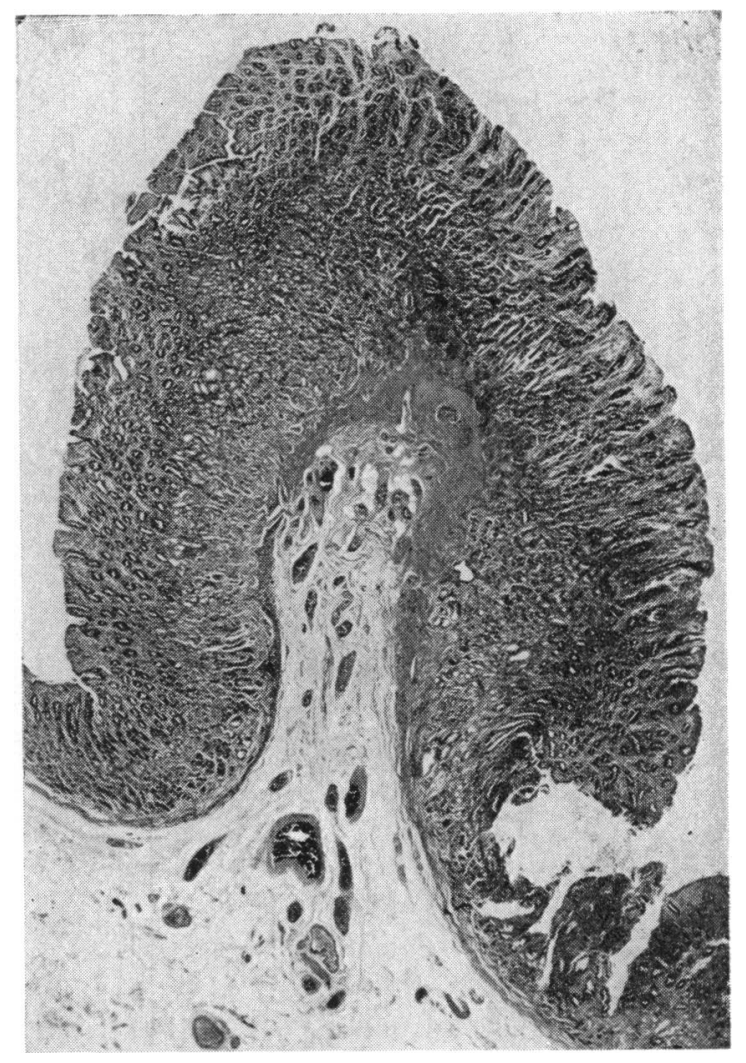

FIG. 3. Photomicrograph $(\times 8)$ of an adenoma from the cardiac end of the stomach. Note the submucosal connective tissue core pushing a thickened and fragmented muscularis mucosae in front of it and how the muscularis mucosae then ramifies in the lamina propria. The superficial layers are intensely infiltrated with inflammatory cells, and an occasional dilated gland is seen. 


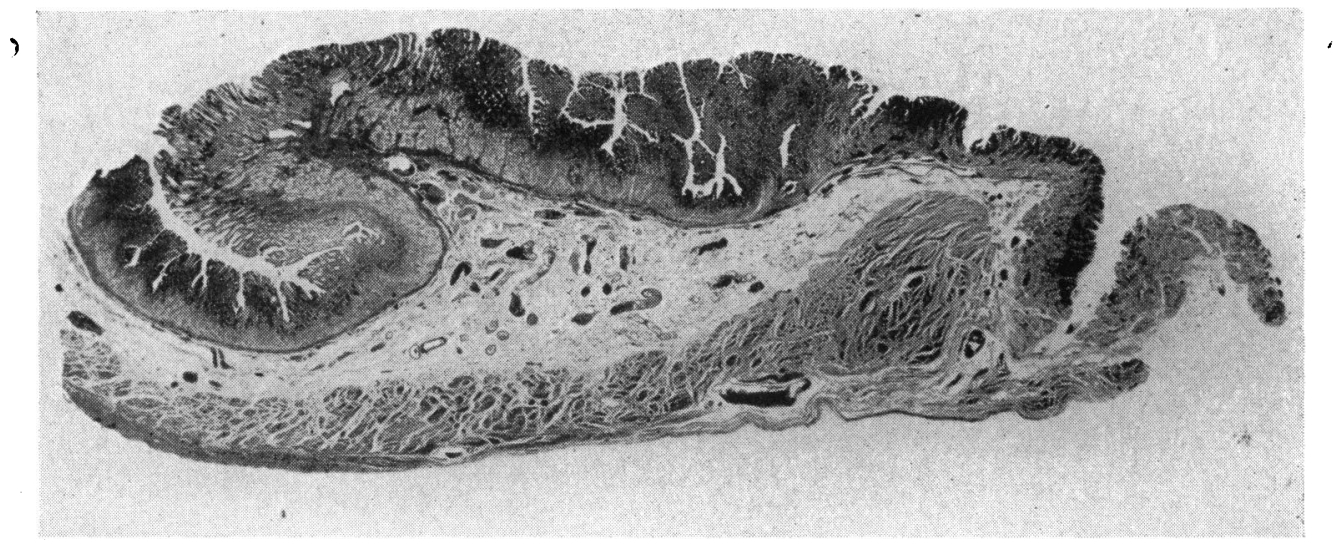

FIG. 4a. Photomicrograph of an adenoma from the pyloric end of the stomach.

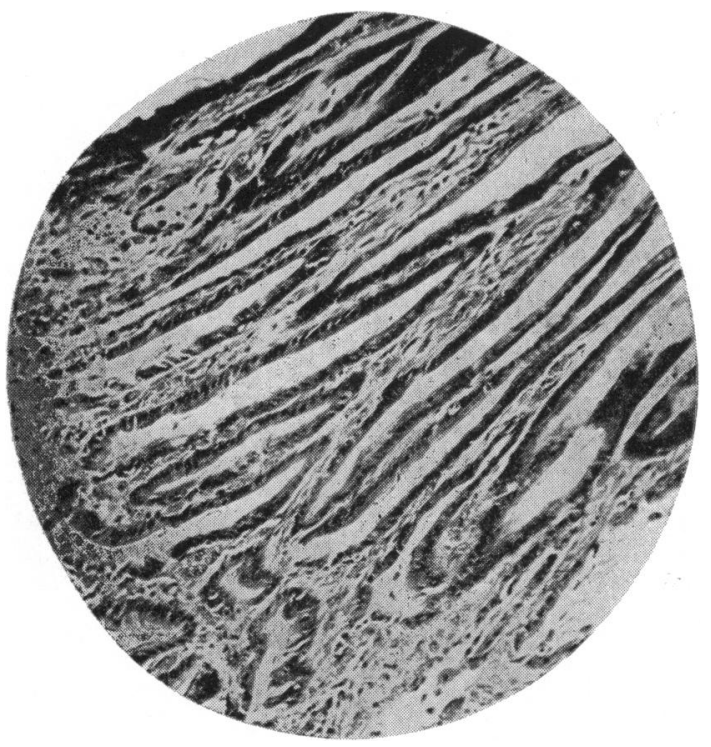

FG. 4b. Photomicrograph $(\times 140)$ of the extreme top left-hand corner of the adenoma shown in Fig. 4 a. Note the crowded cells with relatively little cytoplasm and elongated hyperchromatic nuclei. Mitosis is not usual in the superficial layers of the gastric mucosa but some of these cells show it, although no atypical mitotic figures are seen.

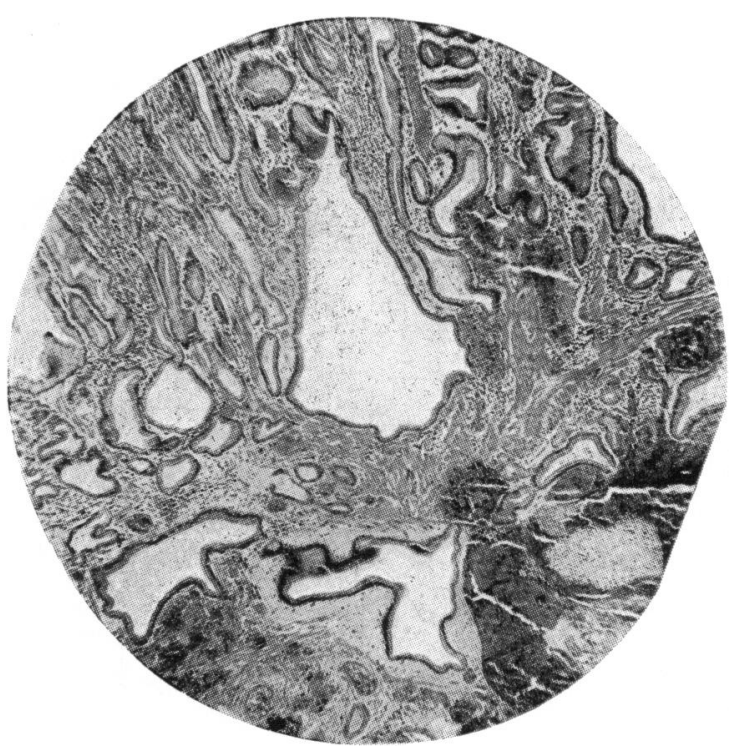

FIG. 5. Photomicrograph $(\times 40)$ showing cystic dilatation and corkscrewing of the gastric glands which are lined by mucoid cells regularly arranged and for the most part in a single layer. The dilated gland at 6 o'clock is herniating through the muscularis mucosae-a not uncommon feature. The mucosa adjacent to the adenoma showed pronounced gastric atrophy. 
smooth and she was discharged on the sixteenth postoperative day, receiving her first injection of vitamin B 12 before departure. Four months later she was progressing well and had returned to her job as a seamstress.

Pathology The specimen (Fig. 2) showed at least $\mathbf{4 0}$ sessile polpys. These were mostly in the cardia but there were also many on either side of the lesser curve and prepyloric region of the greater curve. None was larger than $1 \mathrm{~cm}$. in diameter and some showed superficial ulceration.

Microscopical examination of the lesions at the cardiac end of the stomach (Fig. 3) showed polypoidal adenomata composed of typical specialized gastric glands with numerous parietal and chief cells in the deeper part of the mucosa, and unspecialized, partly mucus-secreting, glandular epithelium in the more superficial part of the mucosa. The latter was heavily infiltrated with large numbers of inflammatory cells, mainly plasma cells. A thickened muscularis mucosae extended into the adenoma and ramified through the lamina propria.

Between the polyps the mucosa showed well-developed chronic gastritis and lymphadenoid hyperplasia; there was almost complete gastric atrophy, and many of the glands were mucoid or totally atrophic. The general picture was one of severe atrophic gastritis.

Examination of the adenomata from the pyloric end of the stomach (Fig. 4a) revealed mucus-secreting cells with pale-staining nuclei deep in the mucosa. These became progressively less mucoid as the surface was approached, and at the surface their nuclei became crowded together and hyperchromatic. Mitoses were present in these superficial cells but they were not numerous. The general appearances of the superficial cells (Fig. 4b) conformed with the description of anaplasia given by Hay (1953), but in none of the sections was there any evidence of frank malignancy. There was some cystic dilatation of the glands (Fig. 5). The lamina propria showed infiltration with plasma cells and eosinophils and a striking ramification within it of the muscularis mucosae, some strands of which almost reached the surface.

Patients with adenomata of the stomach very frequently have atrophic gastritis and the incidence of achlorhydria is of the same order; $85 \%$ of Hay's patients were achlorhydric (Hay, 1953). The present patient was no exception to what is therefore almost the rule and it is interesting to note that abundant parietal cells were nevertheless visible on microscopical examination. This association with gastric atrophy and achlorhydria holds good whether the polyps are single, multiple, benign, or malignant.

CASE 2 Mrs. J. M., aged 62, was admitted to hospital on 5 January 1948, complaining of intense lassitude for one month, loss of appetite, and swollen ankles. No relevant facts were elicited in her previous or family histories. There is no record of her serum protein levels.

On examination she was pale and thin, had small pleural effusions, a liver of which the hard, irregular edge was palpable below the level of the umbilicus, and oedema of the lumbar region and ankles. Her condition deteriorated and she died of a pulmonary embolus on 14 January.

Pathology At necropsy the liver weighed $5.8 \mathrm{~kg}$. and was riddled with secondary deposits from a carcinoma of the stomach. The stomach showed about 12 adenomata scattered over the mucosal surface. Some were pedunculated, but others, close to the upper end of the lesser curve, were sessile and some of these had undergone malignant change. The adjacent mucosa was being involved in the carcinomatous process. Two coronary lymph nodes were replaced by necrotic growth. There were no other polypi in the small or large intestines.

Microscopical examination of one of the polyps revealed an adenoma showing cystic dilatation of the glands. At the bases of the glands there were no chief or parietal cells but granular cells resembling Paneth cells. Mucus-secreting cells persisted up to the surface of the polyp. The muscularis entered and broke up within the lamina propria. The mucosa of the polyp was disorganized to a certain extent but no convincing carcinomatous change was demonstrated in it. However, collections of mucus-secreting carcinoma cells were present in the stalk of the polyp deep to the muscularis and were infiltrating lymphatics. The liver showed deposits of mucus-secreting and poorly differentiated adenocarcinoma resembling that seen in the stalk of the polyp.

\section{DISCUSSION}

The treatment of any disease depends upon an accurate diagnosis and a knowledge of its natural history. When considering multiple polyposis of the stomach this remark is not so trite as it sounds.

The term 'gastric polyposis' enables one to refer with welcome imprecision to several conditions characterized by nodules of gastric epithelium without implying the exact nature of the pathological processes involved in their formation. Setting aside the gastric polyps that are part of the generalized gastrointestinal polyposis of the Peutz-Jeghers syndrome, and which Morson (1960) has suggested may be hamartomatous, gastric polyposis is usually understood to embrace the conditions described by Menétrier, namely, 'polyadenomes polypeux' and 'polyadenomes en nappe' (nappe = velvet). Briefly, the former are generally thought of as true adenomatous formations and the latter as localized areas of hypertrophic gastritis. Although the literature abounds in descriptions of the differences between the two types (Carlson and Ward, 1958; Palumbo, Rugtiv, and Cross, 1951; Paul and Logan, 1947; Pearl and Brunn, 1943; Schindler and McGlone, 1940) the differentiation of adenomatous polyps from hyperplastic polyps may nevertheless on occasion be virtually impossible. Rieniets and Broders (1946), in their minute study of gastric adenomas stated: 'We have not been able satisfactorily to distinguish mucosal hyperplasia from 
fibroadenoma, if the difference exists'. When there is pathological uncertainty such as this it is scarcely to be wondered at that the term 'gastric polyposis' should contine to be used. The cases presented here have been classified as adencmatous because the polyps showed hyperplasia and anaplasia and arose from a gastric mucosa which elsewhere showed histological evidence of severe atrophic gastritis. Pearl and Brunn (1943) regarded the presence of a core of submucosa invaginating the polyp and driving a fragmented muscularis mucosae before it as one of the hallmarks of a gastric adenoma but although this occurred in the cases reported here little significance should be attached to it, as this feature depends on the size of the polyp (Rieniets and Broders, 1945a), is found in the gastric polyps occurring in the Peutz-Jeghers syndrome, can te seen in a transverse section of a hypertrophic gastric ruga (Butz, 1960), and finally because such considerations distract attention from the most important part of the polyp, namely, the epithelium.

Notwithstanding the difficulties of histological classification those who have felt able to recognize these lesions as adenomata have been widely agreed that they are potentially malignant. Single adenomata do not appear to differ from multiple adenomata except that they are commoner and less likely to be associated with malignancy. Presumably the multiple form is the result of a more severe disturbance, both in degree and distribution, of the factors responsible for the maintenance of a normal gastric mucosa. The figures given by various authors of the association between multiple adenomata and carcinoma are set out in Table I. Owing to the diversity of these figures, which in part is probably due to differing criteria of malignancy, it is not possible to

TABLE I

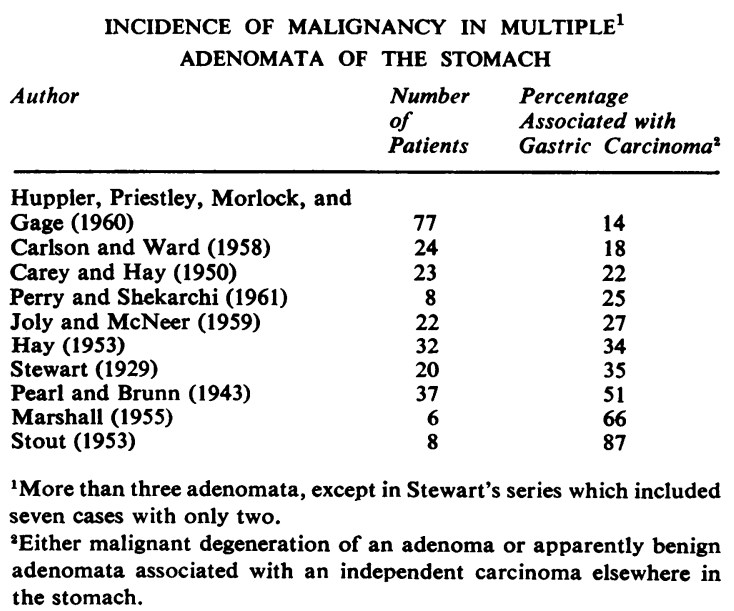

estimate precisely what the risk of malignant degeneration in a given patient might be, but something of the order of 30 to $40 \%$ would not appear unreasonable. Since adenomata of the stomach are rare and carcinoma is common, the former cannot be a frequent precursor of the latter, but it would seem that the conditions that predispose to the development of adenomata are approximately the same as those that favour the development of carcinoma. Rarely this propensity of the gastric mucosa to neoplasia expresses itself as adenomata, more commonly as carcinoma, and sometimes as both together.

It does not follow that when a stomach that is the seat of multiple adenomata develops a carcinoma that the carcinoma develops by malignant degeneration of one of the adenomata, although this can happen as was shown by Berg (1958), Edwards and Brown (1950), Klein and Geller (1951), and Rieniets and Broders (1945b). Rather, the whole gastric epithelium must be regarded as being unstable and the mucosa in between the adenomata just as unreliable as that of the adenomata themselves, a view of which Berg (1958) has provided histological corroboration.

In view of the pathological difficulties and uncertainties it is not surprising that there should also be a divergence of opinion amongst clinicians as to how patients with multiple adenomata should be treated. Pearl and Brunn (1943) were forthright in their advocacy of 'prompt and radical surgical measures ... In some cases the disease remains benign for many years but each case should be treated by operation as soon as the diagnosis is reached ... procrastination is useless and harmful'.

Hay (1953) took a more moderate view of the situation, since he found that adenomata initially assessed by gastroscopy and radicgraphy as being benign seldom became malignant and that those less than $2 \mathrm{~cm}$. in diameter hardly ever became so. On these grounds he pursued a policy of observation rather than operation in suitable patients. However, it is noteworthy that of his 11 patients with multiple adenomata who were simply observed (for an average of 4.2 years) one developed carcinoma of the stomach, and of the eight who underwent subtotal gastrectomy, one developed an inoperable carcinoma in the gastric remnant four years later. Such a policy of conservatism is difficult to practise because it is not always easy to decide whether an adenoma is benign or malignant; moreover, when a very large number of adenomata are distributed over the entire stomach effective surveillance of them all is well-nigh impossible. It has been shown (Carey and Hay, 1948; Edwards and Brown, 1950; Hardt, Steigmann, and Milles, 1948) that although gastro- 
scopy is rather more accurate than radiography in assessing the benign or malignant nature of the lesions neither method is particularly reliable. Thus Hardt et al. (1948) found that about $40 \%$ of polypi failed to show at all on radiological examination and they were uncertain whether the lesions were innocent or not in about a third of their patients. Furthermore, although adenomatosis may affect only the distal half of the stomach the upper third was involved in $63 \%$ of the cases collected by Pearl and Brunn (1943), and this region is notoriously difficult to demonstrate radiologically and parts of it are invisible on gastroscopy. Indeed, an accurate assessment of the distribution of the lesions may only be possible by inspection through a gastrotomy at the definitive operation, and even then an impression of benignity may still be confounded by subsequent microscopical examination.

The risks of waiting and watching were well illustrated by Klein and Geller (1951), who reported the case of a 74-year-old woman who was found on gastroscopy to have three identical and typically benign adenomata. Each was about $1 \mathrm{~cm}$. in diameter. In view of the patient's age and of the high resection that would have been required to achieve their removal it was decided to observe her from time to time. But the patient defaulted and when she eventually returned two years later gastroscopy showed that whereas two of the adenomata were unchanged the third had been completely replaced by a large carcinoma. The dangers of polypectomy, which is little more than a cosmetic operation, are hardly less great. Its unhappy consequences are well illustrated by Edwards and Brown (1950) and Pearl and Brunn (1943). That more extensive but still conservative surgery is insufficient to free the patient of the risk of developing carcinoma of the stomach is particularly well illustrated by Huppler, Priestley,
Morlock, and Gage (1960). They reported 25 patients in whom adenocarcinoma was demonstrated histologically in the tip of a polyp. Of these 25 , one died in hospital and 23 out of the remaining 24 were traced; of those 23 , five $(21.7 \%)$ failed to survive on account of the later development of extensive carcinoma (Beeson, Muschenheim, Castle, Harrison, Ingelfinger, and Bondy, 1960). Carlson and Ward (1958) mention six patients with multiple polyposis treated by partial gastrectomy and two of them subsequently died of gastric carcinoma. Perhaps the most extreme example of the pitfalls of partial gastrectomy is given by Stewart (1929), who described how a patient with multiple adenomata underwent partial gastrectomy only to die five weeks later of a completely undetected carcinoma of the cardia.

\section{TREATMENT}

Taken to their logical conclusion these considerations argue total gastrectomy as the treatment of choice for adenomatosis of the stomach, provided always that the surgeon concerned is an expert total gastrectomist and not just an occasional performer. Figures for the primary mortality of total gastrectomy when performed for benign conditions are naturally scanty but perusal of the literature of the past 10 years has yielded the figures set out in Table II. Although total gastrectomy is a formidable operation with an operative mortality in the region of $20 \%$ when performed for carcinoma, the mortality when performed for innocent conditions is only about $9 \%$ (Table II). The records of patients submitted to total gastrectomy at the Central Middlesex Hospital since 1954 also show that the mortality is halved if the operation is done for a benign rather than a malignant condition. Schuberth (1950), writing of a time (1940-50) when mortality was higher than it is

TABLE II

MORTALITY OF TOTAL GASTRECTOMY PERFORMED FOR BENIGN CONDITIONS ${ }^{1}$

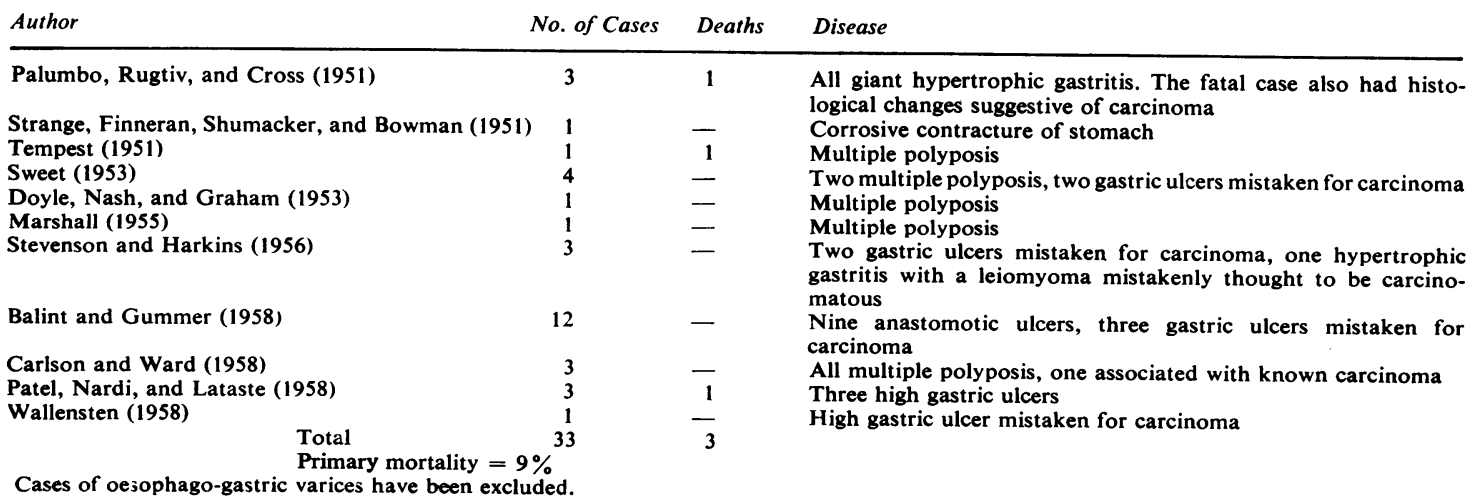


now, likewise found that the mortality from total gastrectomy for benign conditions was much lower $(11 \%)$ than it was when performed for carcinoma.

Total gastrectomy for multiple polyposis was advocated by Wise (1950), who at that time was only able to trace five patients who had been so treated. Sweet (1953) concluded that 'one should not hesitate to perform a total gastrectomy in the treatment of gastric polyps', and Bockus (1943) was of a similar opinion. That the operation has now been carried out on several occasions since Wise's paper may be seen from Table II.

The first patient reported here is alive and well at the time of writing (18 months after total gastrectomy). Few misgivings need be had about performing total gastrectomy on an otherwise fit patient who has symptoms, whose adenomata extend to the cardia, and who is thought by radiography or gastroscopy to have malignant change in one or more adenomata. Such was the state of affairs in the first patient reported above, although the fears of frank malignancy eventually proved groundless. But what of the patient who has few or no symptoms, whose adenomata are chiefly confined to the body and distal part of the stomach, and which to all appearances are benign? Is total gastrectomy still justifiable? If it is accepted that some 30 to $40 \%$ of patients with multiple adenomata will have evidence of malignancy on histological examination (Table I) and that the mortality of total gastrectomy is likely to be in the region of $10 \%$ (Table II), then for a patient such as has just been postulated the safest course would again be total gastrectomy. But if the patient is considered unfit for total gastrectomy the problem becomes one of considerable nicety. The best that could be done for such a patient would be subtotal gastrectomy, with simultaneous polypectomy of the stomach remnant. Such an operation would no longer belong to the realm of cancer prophylaxis except in so far as it reduced the total area of gastric mucosa at risk. An alternative would be regular and close observation, and it is a fact that many patients have been so managed without mishap (Carey and Hay, 1950; Carlson and Ward, 1958; Crohn, 1950; Yarnis et al., 1952), although this contrasts oddly with the experience of Thompson and Oyster (1950) who found that such management resulted in $100 \%$ mortality. If disaster occurs it must then be philosophically regarded as the price paid when attempting to treat patients unfit for radical surgery. The observation of such patients will entail regular barium meals and gastroscopies and these will be a burden to them, but those who do develop malignant changes will be discovered and if these changes happen to develop in the distal part of the stomach then subtotal gastrectomy may yet be a worthwhile procedure. Finally, it must be said that not infrequently patients with adenomatosis of the stomach are virtually moribund on admission and any hope of treatment is forlorn from the outset. Such was the case in the second patient reported above.

In brief, therefore, if a diagnosis of adenomatosis of the stomach is reached by one means or another, then the decision as to whether the lesions are benign or malignant at that particular time will be a matter of very considerable difficulty, the conclusions reached far from reliable, and the future full of hazard if anything less than total gastrectomy the treatment, and this is true no matter what the distribution of the lesions may be.

I am indebted to Dr. F. Avery Jones and Mr. J. W. P. Gummer for permission to publish details of the first patient who was under their care at the Central Middlesex Hospital, and to Dr. C. R. Baxter for similar permission for the second patient, who was under his care at Hillingdon Hospital, Uxbridge. I am particularly grateful to Dr. R. A. B. Drury, morbid anatomist to the Central Middlesex Hospital, for the histological interpretation of the microscopical preparations.

\section{REFERENCES}

Balint, J. A., and Gummer, J. W. P. (1958). Total gastrectomy for benign peptic ulcer. Lancet, 1, 1044-1047.

Beeson, P. B., Muschenheim, C., Castle, W. B., Harrison, T. R., Ingelfinger, F. J., and Bondy, P. K. (1960). Year Book of Medicine, 1960-61 series, p. 494. Year Book Publishers, Chicago.

Berg, J. W. (1958). Histological aspects of the relation between gastric adenomatous polyps and gastric cancer. Cancer (Philad.), 11, 1149-1155.

Bockus, H. L. (1943). Gastro-enterology, Vol. I, p. 710. Saunders, Philadelphia.

Butz, W. C. (1960). Giant hypertrophic gastritis. A report of fourteen cases. Gastroenterology, 39, 183-190.

Carey, J. B., and Hay, L. J. (1948). Gastric polyps. Ibid., 10, 102-107. (1950). Gastric polyps. Ibid., 14, 280-286.

Carlson, E., and Ward, J. G. (1958). Surgical considerations in gastric polyps, gastric polyposis, and giant hypertrophic gastrit is in 74 cases. Surg. Gynec. Obstet., 107, 727-738.

Crohn, B. B. (1950). Discussion at annual meeting of American Gastroenterological Assn., Gastroenterology, 14, 288.

Doyle, R. T., Nash, H. E., Jr., and Graham, J. H. (1953). Diffuse gastric polyposis; Treatment by total gastrectomy. New Engl. J. Med., 249, 477-479.

Edwards, R. V., and Brown, C. H. (1950). Benign disease of the antral portion of the stomach. Benign gastric polyps and their relation to carcinoma of the stomach. Gastroenterology, 16, 531-538.

Hardt, L. L., Steigmann, F., and Milles, G. (1948). Gastric polyps. Ibid., 11, 629-639.

Hay, L. J. (1953). Polyps and adenomas of the stomach. Surgery, 33, 446-467.

Huppler, E. G., Priestley, J. T., Morlock, C. G., and Gage, R. P. (1960). Diagnosis and results of treatment in gastric polyps. Surg. Gynec. Obstet., 110, 309-313.

Joly, D., and McNeer, G. (1959). The clinical significance of small polypoid tumours of the stomach. Bull. N.Y. Acad. Med., $35,328-331$.

Klein, H. C., and Geller, J. S. (1951). Gastric polyp to gastric carcinoma. Gastroenterology, 17, 442-444.

Marshall, S. F. (1955). Gastric tumors other than carcinoma. Report of unusual cases. Surg. Clin. N. Amer., 35, 693-702. 
Morson, B. C. (1960). Familial intestinal polyposis (Correspondence). Brit. med. J., 1, 1807.

Palumbo, L. T., Rugtiv, G. M., and Cross, K. R. (1951). Giant hypertrophic gastritis: its surgical and pathologic significance. Ann. Surg., 134, 259-267.

Patel, J., Nardi, C., and Lataste, J. (1958). Apport, critique des résultats de 412 gastrectomies. Arch. Mal. Appar. dig., 47, 101-122.

Paul, W. D., and Logan, W. P. (1947). Polyps of the stomach with reference to the gastroscopic findings. Gastroenterology, 8, 592-606.

Pearl, F. L., and Brunn, H. (1943). Multiple gastric polyposis. Surg. Gynec. Obstet., 76, 257-281.

Perry, T., Jr., and Shekarchi, K. (1961). Polypoid adenomas of the stomach. Amer. J. Surg., 101, 440-446.

Rieniets, J. H., and Broders, A. C. (1945a). Gastric adenomas: a pathologic study. West. J. Surg., 53, 282-295. (1945b). Ibid., 53, 392-403.

- (1946). Ibid., 54, 21-39.

Schindler, R., and McGlone, F. B. (1940). Familial occurrence of hyperplastic gastric polyps. Arch. Surg. (Chicago), 41, 14831493.

Schuberth, O. (1950). On the value of total gastrectomy in certain cases of peptic ulcer. Acta chir. scand., 100, 434-443.
Stevenson, J. K., and Harkins, H. N. (1956). Total gastrectomy. Analysis of 25 operations performed at a county hospital. Amer. Surg., 22, 363-371.

Stewart, M. J. (1929). Observations on the relation of malignant disease to benign tumours of the intestinal tract. Brit. med. J., 2, 567-569.

Stout, A. P. (1953). Atlas of Tumor Pathology, Sect. VI-Fascicle 21: Tumors of the Stomach. Armed Forces Institute of Pathology, Washington, D.C.

Strange, D. C., Finneran, J. C., Shumacker, H. B., and Bowman, D. E. (1951). Corrosive injury of the stomach. A.M.A. Arch. Surg., 62, 350-357.

Sweet, R. H. (1953). Total gastrectomy by the transthoracic approach. Ann. Surg., 138, 297-310.

Tempest, M. N. (1951). Diffuse polyposis of the stomach. Report of a case. Brit. J. Surg., 38, 525-526.

Thompson, H. L., and Oyster, J. M. (1950). Neoplasms of the stomach other than carcinoma. Gastroenterology, 15, 185-243.

Wallensten, S. (1958). Surgical treatment of gastric ulcer in the vicinity of the cardia. Acta chir. scand., 115, 263-269.

Wise, R. A. (1950). Diffuse polyposis of the stomach. Arch. Surg. (Chicago), 61, 95-101.

Yarnis, H., Marshak, R. H., and Friedman, A. I. (1952). Gastric polyps. J. Amer. med. Ass., 148, 1088-1094. 